\title{
Preface
}

Paul Heitjans*

\section{Lithium Ions in Solids - Between Basics and Better Batteries}

DOI 10.1515/zpch-2015-9033

The present Themed Issue of Zeitschrift für Physikalische Chemie entitled "Lithium Ions in Solids - Between Basics and Better Batteries" comprises contributions from the Bunsen Colloquium "Lithium in Solids: Structure and Dynamics", 6-7 October 2014. This was the third in a series of colloquia in Hannover under the auspices of the Deutsche Bunsengesellschaft für Physikalische Chemie, held before in 2011 and 2009 with the titles "Diffusion in Solids - Methods, Models, and Materials" and "Spectroscopic Methods in Solid State Diffusion and Reactions", respectively [1, 2].

The topic of the 2014 Colloquium has been inspired by and is related to the work of the DFG Research Unit FOR 1277 "Mobility of Lithium Ions in Solids (molife)" of which Leibniz Universität Hannover is the Speaker University. This Forschergruppe is devoted to the fundamentals of Li ion mobility - both fast and slow - in solid state model systems and is tackling questions about, e.g., the influence of structural disorder or low-dimensionality on diffusivity and ion conductivity or the diffusion pathways the elementary jumps of the lithium ions follow.

Interestingly, basic questions like these as well as the model systems studied in FOR 1277 have quite often turned out to be directly relevant also for applicationoriented research, of course, mainly in the field of Li ion batteries.

Therefore, instead of a symposium confined to molife themes, the scope of the Colloquium has been broadened to include besides fundamental studies also application-oriented investigations on ion dynamics and structure of Li containing materials, and eventually battery research contributions. The latter included, e.g., questions about the cyclabilty, electrochemical performance of electrodes and electrolytes, and even the status of post-Li ion batteries.

Reports on Li ion battery research were taken up again in the Summer School "Energy Materials" of the Centre for Solid State Chemistry and New Materials

*Corresponding author: Paul Heitjans, Leibniz Universität Hannover, e-mail: heitjans@pci.uni-hannover.de 
(ZFM) of Leibniz Universität Hannover which directly followed the Bunsen Colloquium.

The intention was to foster cross-fertilization of the seemingly disparate approaches. Accordingly, the papers collected in this issue might help to bridge the gap between basic research on $\mathrm{Li}$ ions in solids and investigations aiming at "building better batteries" or, in other words, to approach the colloquial question "what the electromobility has to do with the mobility of Li ions" - thus citing the titles of two quite different articles [3, 4]. The topics of the 14 papers of this issue range from a theoretical study of competing pathways for Li diffusion in cubic lithium titanium disulfide via the measurement of the kinetics of Li intercalation under pressure in the layered polymorph of this archetypical use-inspired model system to an investigation of the capacity loss due to surface heterogeneity of graphite anodes in lithium ion batteries. The topical range is indicated emblematically by the cover illustration of this issue.

Of course, the Colloquium would not have been possible without the constant help of an enthusiastic team handling countless tasks. I like to cordially thank the members of my group involved in the local organization, in particular Elena Witt, Andre Düvel, Kai Volgmann, Katharina Bösebeck, Vinod Chandran Nair, Florian Strauß and Vanessa Werth. Christian Schröder deserves special thanks for his help in coordinating the Bunsen Colloquium with the subsequent ZFM Summer School at the same venue.

Many thanks go to all colleagues who gave presentations at the Colloquium and/or the Summer School and in particular to those who in addition contributed a paper to the present issue. I also sincerely thank the reviewers for their precious time and valuable comments. Special thanks are due to the members of the editorial staff of Zeitschrift für Physikalische Chemie who kindly helped preparing this issue.

Paul Heitjans

Leibniz Universität Hannover

\section{References}

1. M. Wilkening (Ed.), Diffusion in Solids, Z. Phys. Chem. 226(5-6) (2012) 337.

2. P. Heitjans, M. Martin, and M. Wilkening (Eds.), Spectroscopic Methods in Solid State Diffusion and Reactions, Diffusion Fundam. 12 (2010) 1.

3. M. Armand and J.-M. Tarascon, Building Better Batteries, Nature 451 (2008) 652.

4. P. Heitjans, E. Witt, and C. Schröder, Ionen und Autos - oder: Was die Mobilität von Elektroautos mit der Mobilität von Lithiumionen in Festkörpern zu tun hat, Unimagazin Zeitschrift der Leibniz Universität Hannover 1/2 (2014) 6. 